\title{
Erratum to: Decentralisation and Regional Development
}

\author{
Eva Dick, Karin Gaesing, Daniel Inkoom and Teodoro Kausel
}

\section{Erratum to: E. Dick et al. (eds.), Decentralisation and Regional Development, Springer Geography, DOI 10.1007/978-3-319-29367-7}

The biography for authors' (Wilbard J. Kombe and Eric Oduro-Ofori) and editor (Teodoro Kausel) has been included in the frontmatter. In addition, the book was inadvertently published with an incorrect doctoral title of co-editor Daniel Inkoom on page XV in About the Editors. It should read as "Dr. Daniel Inkoom".

The updated original online version for the book can be found at DOI 10.1007/978-3-319-29367-7

\footnotetext{
E. Dick $(\bowtie)$

Faculty of Spatial Planning, TU Dortmund University, Dortmund, Germany

K. Gaesing

Faculty of Spatial Planning, TU Dortmund University, Dortmund, Germany

D. Inkoom

Department of Planning, Kwame Nkrumah University of Science and Technology, Kumasi, Ghana

T. Kausel

Department of Economics, Administration, Universidad Austral de Chile, Valdivia, Chile

(C) Springer International Publishing Switzerland 2016 